\title{
ENGELS, MARX E O PRAGMATISMO: $A$ ODISSEIA DE WILLIAM ENGLISH WALLING
}

\author{
Paulo Fernando Rocha Antunes ${ }^{1}$ \\ Faculdade de Letras da Universidade de Lisboa (FLUL) \\ (D) https://orcid.org/0000-0002-3603-0127
}

\begin{abstract}
RESUMO:
O presente artigo toma em sua consideração o discreto apêndice do, então socialista, William English Walling - "Socialism and Pragmatism as seen in the Writings of Marx and Engels" - servindo de mote a um regresso à conceção materialista da história, com especial incidência nos escritos de Friedrich Engels. A escolha de Walling assinala-se pelo facto de uma alegada herança de tipo socialista-pragmatista ou marxista-pragmatista atravessar todo o século XX até aos nossos dias. Serão diversos os exemplos, mas parece residir aqui o primeiro esboço de uma tal odisseia.
\end{abstract}

PALAVRAS-CHAVE: Dialética; Materialismo; Pragmatismo; Prática; Socialismo.

\section{ENGELS, MARX AND THE PRAGMATISM: THE WILLIAM ENGLISH WALLING ODYSSEY}

\begin{abstract}
:
his paper takes into account the discrete appendix of William English Walling, then a socialist - "Socialism and Pragmatism as seen in the Writings of Marx and Engels" - viewed to serve as theme for a return to the materialist conception of history, with a focus on the writings of Friedrich Engels. The choice of Walling pointed up itself by the fact that an alleged legacy of socialist-pragmatist or Marxist-pragmatist type goes the entire twentieth century to the present day. The examples will be many, but it seems to be found here the first draft of such an odyssey.
\end{abstract}

KEYWORDS: Dialectic; Materialism; Pragmatism; Practice; Socialist.

\footnotetext{
${ }^{1}$ Doutorando em Filosofia pelo Programa de pós-graduação da Faculdade de Letras da Universidade de Lisboa (FLUL), Lisboa - Portugal. E-mail: pauloantunes@ campus.ul.pt.
} 
Just as "the class struggle" is the central tenet of the political and economic movement, just as "the materialist conception of history" is the central tenet of its philosophical aspect, so pragmatism is the method and the spirit of modern Socialist thought (WALLING, 1913, p.385).

Was den Herren allen fehlt, ist Dialektik. Sie sehn stets nur hier Ursache, dort Wirkung. Daß dies eine hohle Abstraktion ist, daß in der wirklichen Welt solche metaphysische polare Gegensätze nur in Krisen existieren, daß der ganze große Verlauf aber in der Form der Wechselwirkung - wenn auch sehr ungleicher Kräfte, wovon die ökonomische Bewegung weitaus die stärkste, ursprünglichste, entscheidendste - vor sich geht, daß hier nichts absolut und alles relativ ist, das sehn sie nun einmal nicht, für sie hat Hegel nicht existiert (ENGELS, 1967a, p.494).

\section{Introdução}

Em The Larger Aspects of Socialism (1913) do, então socialista, William English Walling (1877-1936) consta um discreto apêndice "Socialism and Pragmatism as seen in the Writings of Marx and Engels" (cf. WALLING, 1913, pp.373-385) - que aqui serve de mote a um regresso à conceção materialista da história (materialistische Geschichtsauffassung), com especial incidência nos escritos de Friedrich Engels (1820-1895) agora que se passaram 120 anos do seu falecimento.

Walling intenta buscar as supostas raízes de um "socialismo pragmatista" em Karl Marx (1818-1883) e Engels, mas é nos escritos deste em que mais se baseia. Em tão curto espaço o autor faz abundantes citações das seguintes obras engelsianas: Herrn Eugen Dührings Umwälzung der Wissenschaft (,Anti-Dühring”) (1877), Die Entwicklung des Sozialismus von der Utopie zur Wissenschaft (1882) e Ludwig Feuerbach und der Ausgang der klassischen deutschen Philosophie (1888) ${ }^{2}$.

\footnotetext{
${ }^{2}$ Die Entwicklung des Sozialismus von der Utopie zur Wissenschaft corresponde a uma parte de „Anti-Dühring”, revista e tornada independente com vista a facilitar a compreensão do seu conteúdo sem ter de se passar por uma obra tão extensa como a que visava uma crítica a Eugen Dühring (1833-1921). Foi publicada pela primeira vez em tradução de Paul Lafargue (1842-1911) para francês - Socialisme Utopique et Socialisme Scientifique (1880). Não obstante o pendor essencialmente crítico, da primeira destas obras, ao Privatdozent, Engels acabou por expor as principais caraterísticas da conceção materialista da história. Quanto à última das três obras referidas - Ludwig Feuerbach und der Ausgang der klassischen deutschen Philosophie - Engels estava mais preocupado em dar conta da importância que Ludwig Feuerbach (1804-1872) teria tido nele e em Marx, porém, criticando-o e mostrando onde consideraram necessário superar o humanista.
} 
Por seu turno, Marx terá um papel secundário no apêndice de Walling, sendo quase sempre convocado por intermédio de Engels. É por isso que Marx será apenas convocado quando por via do seu amigo for chamado a intervir. Por exemplo, a referência que é feita no texto a Das Kapital (1867) surge através do que Engels citou do seu companheiro no primeiro daqueles escritos acima referidos.

Não obstante, não se descura que tanto Marx como Engels se influenciaram mutuamente. Os escritos de ambos constituem o corpus fundador daquilo que hoje é conhecido por marxismo, e talvez só se chame assim porque o primeiro faleceu antes e o segundo o homenageou como pôde, quer publicando as suas obras postumamente (o resto de Das Kapital 1885 e 1894, principalmente) quer atribuindo-lhe a primazia quanto à conceção materialista da história (por exemplo, cf. ENGELS, 1962, p.264).

Enfim, o que mais importa para o efeito aqui pretendido será remontar o mais próximo possível às origens de uma "conciliação" entre o socialismo e o pragmatismo, e procurar perceber se faz justiça à conceção materialista da história dos dois autores alemães.

Poderão surgir dúvidas em relação à escolha de um tão obscuro autor norte-americano para realizar o esforço anunciado, no entanto, parece residir em Walling o primeiro esboço de uma tal odisseia ${ }^{3}$, herança de tipo socialista-pragmatista ou marxista-pragmatista que atravessou todo o século $\mathrm{XX}$ até aos nossos dias ${ }^{4}$.

Quanto às passagens em alemão de que se fará uso, chama-se a atenção para as respetivas traduções creditadas em Referências bibliográficas, mas também para o facto de que sofreram alterações, quer por via de uma melhor adequação ao que os autores expressavam, quer por via de uma comparação com versões inglesas. Todas as restantes passagens traduzidas para português, mas não creditadas em bibliografia, são da nossa inteira responsabilidade.

${ }^{3}$ Não é escondida a fonte inspiradora da expressão escolhida para ilustrar o presente objeto de reflexão - "odisseia" (odyssey). Esta inspiração provém de um texto de Richard Schneirov (1948-) (cf. 2003, pp.404-430), ainda que não tenha intenção de seguir pelo caminho que o seu autor desenvolveu, uma vez que se tratou de uma visão panorâmica do que foi o progresso filosófico-político de Walling. Recorda-se ainda que, não por acaso, Schneirov foi o fundador da William English Walling Society (2000-2004). Recorda-se ainda que Walling foi um reformador do American labor, um socialista republicano, mais tarde rendido ao que viria a ser a social-democracia (em dissidência com o movimento comunista internacional); foi também responsável pelo National Women's Trade Union League e pelo National Association for the Advancement of Colored People (NAACP); e durante seis anos trabalhou a tempo inteiro para a American Federation of Labor (AFL). A sua influência no movimento dos trabalhadores norte-americano não será, seguramente, despicienda (cf. BOYLAN, 1998, passim).

${ }^{4}$ Serão diversos os exemplos na orientação e no propósito de uma tal herança, quer para atacar: «O próprio Marx teria concordado com uma abordagem prática para a crítica do seu método, pois ele foi um dos primeiros filósofos a desenvolver os pontos de vista que mais tarde foram chamados de 'pragmatismo'» - «Marx himself would have agreed with such a practical approach to the criticism of his method, for he was one of the first philosophers to develop the views which later were called 'pragmatism'»(POPPER, 1945, p.80); quer para 


\section{Walling e o Pragmatismo nos escritos de Engels e Marx}

Walling escrevia à época em que o pragmatismo se tornava a filosofia dominante nos E.U.A., quando o pragmatista John Dewey (18591952) - de quem não esconde a influência, referindo-o pelo menos uma vez ao longo do seu curto apêndice e abundantemente na sua obra -, já era um dos filósofos-pedagogos mais conceituados no seu país e além-fronteiras.

$\mathrm{O}$ esforço para procurar conciliar o socialismo com uma nova conceção de mundo justificava-se para alguns socialistas americanos (entre outros), resumidamente, no âmbito de uma ampla discussão no movimento socialista internacional, porquanto Eduard Bernstein (1850-1932) punha na ordem do dia o reformismo; se previa uma grande guerra; e, o debate na II Internacional (1889-1920) vivia o auge da sua polémica ${ }^{5}$. Este seria o panorama geral a partir do qual o autor procurava "atualizar" os fundadores do socialismo moderno.

Segundo o autor americano: «[...] Marx e Engels começaram decididamente na direção do pragmatismo [...]; de um modo geral eles foram pragmatistas, mas perderam algumas das caraterísticas mais básicas e essenciais [basic and essential features] da nova filosofia», (WALLING, 1913, p.373) ${ }^{6}$. A partir do seu apêndice, o autor procurava dar conta do que de mais pragmatista caberia aos dois alemães e onde residiria a razão pela qual haviam perdido as "caraterísticas mais básicas e essenciais" da nova filosofia, entenda-se, do pragmatismo.

De acordo com Walling - que considerava o essencial da conceção materialista da história concebido entre 1848-1875, precisamente uma

\footnotetext{
defender: «Juntamente com Marx [...] o pragmatismo surge como a única abordagem que abraça a modernidade nas suas formas mais radicais, e reconhece as suas contingências, sem sacrificar a própria finalidade da Filosofia Ocidental - ou seja, para testar explicações sobre quem somos e quem gostaríamos de ser, como indivíduos, como membros das nossas comunidades, e como pessoa überhaupt [em geral] - isto é, como homem» - «Alongside Marx [...] pragmatism emerges as the only approach that embraces modernity in its most radical forms, and acknowledges its contingencies, without sacrificing the very purpose of Western philosophy - namely, to try out explanations of who we are and who we would like to be, as individuals, as members of our communities, and as person überhaupt - that is, as man» (HABERMAS, 2002, p.229). Um outro exemplo de um autor atual que, partindo de uma perspetiva pragmatista, procura dialogar com Marx, pode ser encontrado em Roberto Mangabeira Unger (1947-), (cf. UNGER, 2007, passim).

${ }^{5}$ De acordo com Walling (cf. 1913, p.380), Lafargue, Franz Mehring (1846-1919) e Karl Kautsky (1854-1938) eram as vozes mais altissonantes dentro do movimento socialista, baseando-se mais no último deles. Outros socialistas bastante conhecidos também faziam parte da II Internacional, por exemplo, Vladimir Lénine (1870-1924) e Rosa Luxemburgo (1971-1919) entre outros.

${ }^{6}$ «[...] Marx and Engels made a decided beginning in the direction of pragmatism [...]; broadly speaking they were pragmatists, but they missed some of the most basic and essential features of the new philosophy».
} 
geração anterior ao pragmatismo (cf. WALLING, 1913, p.373) ${ }^{7}-$, teria sido Engels quem mais se aproximara do pragmatismo dos seus dias. Não fora por acaso que o autor americano se servira de obras engelsianas posteriores ao período referido.

Para o efeito que anunciava, Walling serviu-se da seguinte passagem do fundador alemão: "“um travão é colocado, de uma vez por todas, à demanda por soluções definitivas e verdades eternas; ter-se-á sempre consciência das necessárias limitações de todo o conhecimento adquirido, da sua natureza hipotética devido às circunstâncias em que foi alcançado"», (ENGELS apud WALLING, 1913, p.374, grifos nossos) ${ }^{8}$.

Quer dizer, ao colocar um travão à conceção de uma "solução definitiva" e "verdade eterna", o ser humano, o socialista em particular, tomaria a atitude científica expetável ${ }^{9}$. Portanto, o conhecimento teria um caráter relativo, não havendo lugar para qualquer posição que se apoiasse naquele tipo de "solução" ou de "verdade" 10.

No sentido de um outro método para averiguar a verdade, ainda que relativa, Walling assumia a crítica de Engels desferida àqueles que se opunham à possibilidade de conhecer "verdades práticas", como seria o caso de David Hume (1711-1776) e de Immanuel Kant (1724-1804). Uma vez que era preciso conhecer-se alguma coisa (pois não se poderia suster em permanente ceticismo na ausência de um conhecimento absoluto...). Assim, Walling buscou respaldo em duas das mais conhecidas passagens de Engels em crítica à incognoscibilidade da "coisa em si" (Ding an sich):

A mais destrutiva refutação desta fantasia filosófica [a fantasia do idealismo], como aliás de todas as outras, é a prática [na tradução inglesa: actual results; e no original: Praxis],

\footnotetext{
${ }^{7}$ Sem que o autor alguma vez o mencione, importa lembrar de que se trata de uma geração anterior ao conhecido texto fundador do pragmatismo - "How to make our ideas clear" (1878) da autoria de Charles Sanders Pierce (1839-1914).

${ }^{8}$ «"a stop is put, once and for all, to the demand for final solutions and for eternal truths; one is firmly conscious of the necessary limitations of all acquired knowledge, of its hypothetical nature, owing to the circumstances under which it has been gained"».

9 Por exemplo, diz um dos mais conhecidos fundadores do pragmatismo e uma das inspirações de Walling, William James (1842-1920): «O pragmatista agarra-se aos factos e à concretude [concreteness], observa a verdade no seu trabalho em casos particulares, e generaliza. A verdade, para ele, torna-se um nome-de-classe [class-name] para todos os tipos definidos de valores-funcionais [working-values] na experiência» - «The pragmatist clings to facts and concreteness, observes truth at its work in particular cases, and generalizes. Truth, for him, becomes a class-name for all sorts of definite working-values in experience» (JAMES, 1908, p.68).

${ }^{10}$ Em conformidade, Engels tomava o "ponto de vista evolutivo" (evolutionary standpoint) segundo o autor (cf. WALLING, 1913, p.374). De acordo com Walling, a teoria da evolução com base em Darwin teria vindo alterar o desenvolvimento do conhecimento científico no tempo de Marx e Engels, porém, à sua época, mesmo mantendo a sua importância, considerava mais relevantes para o desenvolvimento científico a antropologia, a sociologia e a psicologia (cf. WALLING, 1913, p.378).
} 
sobretudo o experimento e a indústria. Se conseguimos provar a justeza da nossa conceção de um fenómeno natural fazendo-o nós próprios, produzindo-o com a ajuda das suas condições e, sobretudo, fazendo-o servir os nossos fins, põe-se fim à 'coisa em si’ inapreensível de Kan (ENGELS apud WALLING, 1913, pp.374-375) ${ }^{11}$.

Imediatamente a seguir, o autor americano lembra outra passagem de Engels, agora do prefácio de Die Entwicklung des Sozialismus von der Utopie zur Wissenschaft (escrito propositadamente pelo próprio autor alemão em inglês para a edição inglesa de 1892):

Mas antes de existir a argumentação houve a ação. Im Anfang war die Tat [Ao princípio era a ação]. E a ação humana resolvera a dificuldade muito antes de o engenho humano a inventar. A prova do pudim está no comer [The proof of the pudding is in the eating]. A partir do momento em que pomos estes objetos ao nosso uso próprio, de acordo com as qualidades que neles percebemos, submetemos a um teste infalível a exatidão ou não das nossas perceções sensoriais [sense-perceptions]. Se estas perceções estiverem erradas, então a nossa estimativa do uso a dar a um objeto tem também de estar errada, e a nossa tentativa tem de falhar. Mas se somos bem-sucedidos descobrimos que o objeto está de acordo com a ideia que temos dele, e que serve para o fim a que o destinámos, então teremos uma prova positiva [positive proof] de que as nossas perceções do objeto e das suas qualidades, nesta medida, estão de acordo com a realidade que existe fora de nós próprios. E sempre que nos encontramos perante um fracasso, não levamos, de um modo geral, muito tempo a reconhecer a causa do nosso fracasso; descobrimos que a perceção sobre a qual agimos ou era incompleta e superficial, ou aparecia combinada com os resultados de outras perceções de uma forma que estas não justificavam - aquilo a que chamamos um raciocínio imperfeito [defective reasoning] (ENGELS apud WALLING, 1913, p.375, grifos do texto original; a expressão que vem em alemão do Fausto de Goethe não foi referida pelo autor americano, porém consta como tal na versão de Engels) ${ }^{12}$.

\footnotetext{
${ }^{11}$ «The most destructive refutation of this as of all other fixed philosophic ideas is actual results, namely, experiment and industry. If we can prove the correctness of our idea of an actual occurrence by experiencing it ourselves and producing it from its constituent elements, and using it for our own purposes, into the bargain, the Kantian phrase, 'Ding an Sich' (thing in itself) ceases to have any meaning» - «Die schlagendste Widerlegung dieser wie aller andern philosophischen Schrullen ist die Praxis, nämlich das Experiment und die Industrie. Wenn wir die Richtigkeit unsrer Auffassung eines Naturvorgangs beweisen können, indem wir ihn selbst machen, ihn aus seinen Bedingungen erzeugen, ihn obendrein unsern Zwecken dienstbar werden lassen, so ist es mit dem Kantschen unfaßbaren „Ding an sich" zu Ende.» (ENGELS, 1962, p276).

12 «Before there was argumentation, says Engels elsewhere, there was action. And human action had solved the difficulty long before human ingenuity invented it. The proof of the
} 
$\mathrm{O}$ enunciado à primeira vista parece assemelhar-se à perspetiva pragmatista. É-se, pois, tentado a recordar, uma vez que o autor não o fez, o que era dito, por exemplo, por Dewey: «[...] o objeto de conhecimento [object of knowledge] é prático [practical] no sentido de que depende de um tipo específico de prática para a sua existência - para a sua existência como objeto de conhecimento» $\left(1916\right.$, p.334) ${ }^{13}$. De acordo com Walling, a prática encontrava-se na base de um critério de verdade relativa tanto para o socialismo moderno como para o pragmatismo.

Por conseguinte, para o autor americano, tudo isto seria suficiente para resultar numa "conciliação" bem-sucedida. Ora, quer para uma teoria, quer para a outra, parecia estar ultrapassada a questão de uma "coisa em si" (fronteira que um cético não atravessaria...) -dada a possibilidade prática de fazer dela uma "coisa para nós" -; tal como parecia estar ultrapassada qualquer demanda por um conhecimento absoluto - pela prática humana tal conhecimento jamais seria possível.

Posta a condição de verdade na prática, Walling dirige-se às famosas Thesen über Feuerbach (1845) de Marx (publicadas pela primeira vez como apêndice de Ludwig Feuerbach und der Ausgang der klassischen deutschen Philosophie), citando desde logo a primeira delas:

O principal defeito de todo o materialismo até aos nossos dias, o de Feuerbach incluído, é que as coisas, a realidade, a sensação são tomadas apenas sobre a forma do objeto ou da contemplação; mas não como atividade sensível humana, 'práxis'. ... Feuerbach quer, é verdade, objetos sensíveis realmente distintos dos objetos do pensamento, mas não toma a própria atividade humana como atividade objetiva. Ele considera, por isso, na 'Wesen des Christenthums' [1841], apenas a atitude teorética como a genuinamente humana, ao passo que a práxis é tomada e fixada apenas na sua forma de manifestação sórdida (MARX apud WALLING, 1913, p.376) 14

pudding is in the eating. From the moment we turn to our own use these objects, according to the qualities we perceive in them, we put to an infallible test the correctness or otherwise of our sense-perceptions. If these perceptions have been wrong, then our estimate of the use to which an object can be turned must also be wrong, and our attempt must fail. But if we succeed in accomplishing our aim, if we find that the object does agree with our idea of it, and does answer the purpose we intended it for, then that is positive proof that our perceptions of it and of its qualities, so far, agree with reality outside ourselves. And whenever we find ourselves face to face with a failure, then we generally are not long in making out the cause that made us fail; we find that the perception upon which we acted was either incomplete and superficial, or combined with the results of other perceptions in a way not warranted by them - what we call defective reasoning».

13 «[...] the object of knowledge is practical in the sense that it depends upon a specific kind of practice for its existence - for its existence as an object of knowledge».

14 «The chief lack of all materialistic philosophy up to the present, including that of Feuerbach, is that the thing, the reality, sensation is only conceived of under the form of the 
O autor americano faz sua a crítica a uma "atitude teorética" privilegiada em relação à atividade humana, à prática. Visto que sem a prática não seria possível qualquer conhecimento, qualquer teoria, que não fosse apenas pura especulação, pura abstração, isto é, acabava por não haver sequer conhecimento.

Apoiar-se numa prática em detrimento de uma conceção de tipo "absoluto" ou ainda evitar quedar-se em permanente ceticismo, parece ser o que mais qualificava os fundadores do socialismo moderno como protopragmatistas, dado o exposto por Walling. «A conceção "materialista" da história de Marx e Engels é puramente pragmática» (Marx's and Engels' "materialistic" conception of history is purely pragmatic, WALLING, 1913, p.378), atestava.

Contudo, como já referido, algo fora responsável pela perda de Marx e Engels de algumas das "caraterísticas mais básicas e essenciais" da "nova filosofia", daquilo que Walling entendia dever ser o socialismo do seu tempo - consequentemente, pragmatista. A perda daquelas caraterísticas não se ficava apenas pelos dois autores alemães terem falhado uma geração filosófica, até porque os escritos de Engels evocados são contemporâneos às primeiras formulações pragmatistas. Então, a causa teria de residir em algo mais caraterístico dos escritos de ambos.

$\mathrm{O}$ autor americano concedia todo o crédito a Engels por este criticar, como aquele entendia ser mister pragmatista, as "soluções definitivas" e as "verdades eternas". No entanto, Walling não estava convencido de que os dois fundadores o tivessem respeitado sempre, talvez por isso lembrasse: «[...] a filosofia destes pais da Teoria socialista não é de nenhuma maneira "materialista" no sentido comum» (I have already indicated that the philosophy of these fathers of Socialist theory is by no means "materialistic" in ordinary sense», WALLING, 1913, p.378). Porventura no seu caráter incomum residisse a razão da perda das tais caraterísticas da nova filosofia.

Aquilo em que consistia o caráter incomum do materialismo de Marx e Engels seria o aparente privilégio dado ao fator económico. Mas não só, por detrás deste privilégio estaria o facto de ambos terem tido em Georg W. F. Hegel (1770-1831) uma das suas principais influências, o que teria afetado o pragmatismo dos dois. Segundo o autor americano: «O pragmatismo de Marx e Engels, todavia, foi muito afetado pelo seu esforço de adaptar a Filosofia hegeliana para fins Socialistas, [...] nenhum homem

object which is presented to the eye, but not as human sense activity, "praxis".... Feuerbach is willing, it is true, to distinguish objects of sensation from objects existing in thought, but he conceives of human activity itself as not being objective activity. He, therefore, in the "Wesen des Christenthums", regards only theoretical activity as generally human, while the 'praxis' is conceived and fixed only in its disgusting form». 
que alguma vez haja vivido foi, talvez, mais afastado de ser um pragmatista do que foi Hegel» (WALLING, 1913, p.379) ${ }^{15}$.

A dialética hegeliana estaria na base de todas as caraterísticas "antiquadas" (antiquated) dos dois autores alemães (cf. WALLING, 1913, p.382). Com vista a ilustrar essa ideia, Walling utilizou algumas passagens de ambos, com especial ênfase para uma passagem de Das Kapital que Engels havia citado no seu ,Anti-Dühring”:

O modo capitalista de produção, e de apropriação, quer dizer propriedade privada capitalista, constitui a primeira negação de propriedade privada individual que se funda no trabalho de indivíduos, a negação da produção capitalista será autoproduzida [self-produced] com a necessidade de um processo natural, etc. (MARX apud WALLING, 1913, p.382, grifos nossos) ${ }^{16}$.

Para o autor americano esta afirmação de Marx denunciava uma "necessidade natural" para a superação do capitalismo, o que levaria ao dogmatismo (as tais certezas de tipo absoluto, primeiramente rejeitadas), uma vez que parece incorrer numa espécie de "determinismo económico". Walling entende que o mesmo tipo de dogmatismo poderia ser encontrado na perspetiva que presidia à consideração da Natureza por parte de Engels. Deste citou:

O ponto de vista [da dialética da Natureza] é atingido sob a compulsão da massa de factos científicos, chegar-se-á lá mais facilmente abordando o caráter dialético desses factos com a consciência das leis do pensamento dialético. De qualquer modo, o escopo da ciência tem feito tais progressos que já não pode fugir à compreensão dialética (ENGELS apud WALLING, 1913, p.382, grifos do autor) ${ }^{17}$.

Segundo o autor americano, nada disto se verificava na ciência da Natureza do seu tempo: nem a Natureza se processava dialeticamente, nem a ciência fazia da dialética a sua metodologia. Uma tal perspetiva seria sumamente antiquada e redundaria, precisamente, num dogmatismo à guisa hegeliana.

\footnotetext{
15 «The pragmatism of Marx and Engels, however, was much affected by their effort to adapt the Hegelian philosophy to Socialist purposes, [...] no man that ever lived was perhaps further from being a pragmatist than was Hegel».

16 «The capitalistic method of production and method of appropriation, that is to say capitalistic private property, is the first negation of individual private property founded on labor of individuals, the negation of capitalistic production will be self-produced with the necessity of a natural process, etc.».

17 «The view is reached under the compulsion of the mass of scientific facts, and one reaches it the more easily by bringing to the dialectic character of these facts a consciousness of the laws of dialectic thought. At all events, the scope of science is now so great that it no longer escapes the dialectic comprehension».
} 
Walling não esconde entender que as teses de Hegel poderiam ter sido revolucionárias em 1840, não obstante, não o seriam mais. Deste modo, de acordo com o autor, Marx e Engels, haviam tentado, mormente Engels, interpretar Hegel pragmaticamente - se este ajudara a perceber que tudo era finito, isso não passava de uma leitura pragmatista dos seus escritos (cf. WALLING, 1913, pp.380). Assim, a principal razão da perda, por Marx e Engels, das "caraterísticas básicas e essenciais" do pragmatismo residiria na influência da dialética hegeliana.

Por conseguinte, o melhor que os dois fundadores haviam legado às gerações socialistas ulteriores, teria sido um esboço preliminar de pragmatismo. Não obstante, os dois autores estariam perdoados por reconhecer as limitações do seu tempo e, porventura, por outros socialistas terem seguido o seu exemplo (cf. WALLING, 1913, p.384) ou, segundo Walling, por Engels ter deixado uma espécie de confissão epistolar, publicada ainda em vida (cf. ENGELS, 1967b):

\begin{abstract}
Marx e eu somos parcialmente responsáveis pelo facto de que, por vezes, os mais jovens tenham dado mais relevo ao lado económico do que aquilo que este merecia. Face aos ataques dos nossos adversários, era necessário, para nós, enfatizar o princípio dominante [na tradução inglesa: dominant principle; e no original: Hauptprinzip] por eles negado e nem sempre tivemos tempo, lugar ou oportunidade de deixar a outros fatores, que estavam envolvidos na ação e reação recíproca [na tradução inglesa: mutual action; e no original: Wechselwirkung], obter o que mereciam (ENGELS apud WALLING, 1913, p.379) ${ }^{18}$.
\end{abstract}

Enfim, é caso para dizer, na esteira wallingiana, que o "socialismo pragmatista" será uma evolução do marxismo, do socialismo moderno (pelo menos até à sua época), e que nele residiria a base suscetível de garantir o afastamento das teses fundadoras relativamente a quaisquer interpretações dogmáticas (mais propriamente, dialéticas). Como aludido em epígrafe, $o$ pragmatismo seria então o espírito e o método do pensamento Socialista moderno ${ }^{19}$.

\footnotetext{
${ }^{18}$ «Marx and I are partly responsible for the fact that the younger men have sometimes laid more stress on the economic side than it deserves. In meeting the attacks of our opponents it was necessary for us to emphasize the dominant principle denied by them, and we did not always have the time, place, or opportunity to let the other factors which were concerned in the mutual action and reaction get their deserts» - «Daß von den Jüngeren zuweilen mehr Gewicht auf die ökonomische Seite gelegt wird, als ihr zukommt, haben Marx und ich teilweise selbst verschulden müssen. Wir hatten, den Gegnern gegenüber, das von diesen geleugnete Hauptprinzip zu betonen, und da war nicht immer Zeit, Ort und Gelegenheit, die übrigen an der Wechselwirkung beteiligten Momente zu ihrem Recht kommen zu lassen» (ENGELS, 1967b, p.465).

${ }^{19}$ Não resta espaço para o seu comentário, mas chama-se a atenção que na obra, na qual se encontra o presente apêndice, o autor procura, inspirado por Dewey, abordar precisamente
} 


\section{Engels nos seus próprios escritos}

Parece que o exercício que compete fazer no momento que se segue é o de regressar ao contexto das passagens de Engels de que Walling se serviu.

Comecemos pela primeira passagem onde o autor americano assinala a oposição engelsiana às "soluções definitivas" e às "verdade eternas":

[...] se partirmos constantemente deste ponto de vista [Gesichtspunkt] na investigação, deixaremos de uma vez por todas de pedir soluções definitivas [endgültiger Lösungen] $e$ verdades eternas [ewiger Wahrheiten]; ter-se-á sempre consciência do caráter necessariamente limitado de qualquer conhecimento adquirido, da sua dependência em relação às condições em que foi adquirido; não nos deixaremos mais dominar pelas oposições irredutíveis da velha metafísica entre o verdadeiro e o falso, o bem e o mal, o idêntico e o diferente, o necessário e o contingente; sabe-se que essas oposições não têm senão um valor relativo, que o que reconhecemos como verdadeiro agora tem o seu lado falso escondido, que aparecerá mais tarde, tal como o que é hoje reconhecido por falso tem o seu lado verdadeiro graças ao qual pôde precedentemente ser considerado verdadeiro; que o que se afirma necessário é composto de puros acasos e que o pretenso acaso é a forma sob a qual se esconde a necessidade - e assim sucessivamente (ENGELS, 1962, pp.293-294, a grifo o que foi referido por Walling ${ }^{20}$.

Dado o contexto da passagem parece que o autor americano retirou aquilo que mais se adequava aos seus propósitos - a crítica à demanda por "soluções definitivas" e "verdade eternas" - e deixou de lado, não apenas quanto a este excerto mas em todo o seu apêndice, a crítica ao ponto de vista da metafísica que Engels visava diretamente ao criticar aquelas, como pelas linhas seguintes se percebe. Talvez Walling o tenha deixado de lado por esta

os principais fatores que considera terem sido descurados pelos dois fundadores em favor do fator económico.

${ }^{20}$ «Geht man aber bei der Untersuchung stets von diesem Gesichtspunkt aus, so hört die Forderung endgültiger Lösungen und ewiger Wahrheiten ein für allemal auf; man ist sich der notwendigen Beschränktheit aller gewonnenen Erkenntnis stets bewußt, ihrer Bedingtheit durch die Umstände, unter denen sie gewonnen wurde; aber man läßt sich auch nicht mehr imponieren durch die der noch stets landläufigen alten Metaphysik unüberwindlichen Gegensätze von Wahr und Falsch, Gut und Schlecht, Identisch und Verschieden, Notwendig und Zufällig; man weiß, daß diese Gegensätze nur relative Gültigkeit haben, daß das jetzt für wahr Erkannte seine verborgene, spatter hervortretende falsche Seite ebensogut hat wie das jetzt als falsch Erkannte seine wahre Seite, kraft deren es früher für wahr gelten konnte; daß das behauptete Notwendige sich aus lauter Zufälligkeiten zusammensetzt und das angeblich Zufällige die Form ist, hinter der die Notwendigkeit sich birgt - und so weiter». 
crítica à metafísica partir de um ponto de vista dialético, que já se podia encontrar em Hegel (cf. HEGEL, 1989, §§ 30-33) ${ }^{21}$. Aliás, Engels, imediatamente antes, contextualiza o seu ponto de vista:

A grande ideia fundamental [große Grundgedanke] segundo a qual o mundo não deve ser considerado como um complexo de coisas acabadas, mas como um complexo de processos em que as coisas, aparentemente estáveis, tanto como os seus reflexos intelectuais no nosso cérebro, os conceitos, estão submetidos a uma mudança ininterrupta [ununterbrochene Veränderung] de devir e de morte e que, finalmente, apesar de todos os acasos aparentes e de todos os retrocessos momentâneos, um desenvolvimento progressivo acaba por afirmar-se - esta grande ideia fundamental penetrou, sobretudo depois de Hegel, tão profundamente na consciência corrente que, sob esta forma geral, quase não encontrou mais contradição (1962, p.293, grifos do autor) ${ }^{22}$.

${ }^{21}$ Walling já havia sonegado outras passagens relevantes, por exemplo: «[...] e da coleção dos seus resultados com a ajuda do pensamento dialético», tal como vem na tradução de que o autor americano se serve: «[...] and the collection of their results by means of the dialectic mode of thought» (ENGELS, 1962, pp.48-49). Walling apagou-o da tradução substituindo uma vírgula, e o que se lhe segue, por uma exclamação: «As regards all philosophers, their system is doomed to perish and for this reason, because it emanates from an imperishable desire of the human soul, the desire to abolish all contradictions. But if all contradictions are once and for all disposed of, we have arrived at the so-called absolute truth, history is at an end, and yet it will continue to go on, although there is nothing further left for it to do thus a newer and more insoluble contradiction. So soon as we have once perceived and to this perception no one has helped us more than Hegel himself that the task thus imposed upon philosophy signifies that a single philosopher is to accomplish what it is only possible for the entire human race to accomplish, in the course of its progressive development as soon as we understand that, it is all over with philosophy in the present sense of the word. In this way one discards the absolute truth, unattainable for the individual, and follows instead the relative truths attainable by way of the positive sciences!» (WALLING, 1913, pp.376-377, grifos do autor) - «Bei allen Philosophen ist grade das „System” das Vergängliche, und zwar grade deshalb, weil es aus einem unvergänglichen Bedürfnis des Menschengeistes hervorgeht: dem Bedürfnis der Überwindung aller Widersprüche. Sind aber alle Widersprüche ein für allemal beseitigt, so sind wir bei der sogenannten absoluten Wahrheit angelangt, die Weltgeschichte ist zu Ende, und doch soll sie fortgehn, obwohl ihr nichts mehr zu tun übrigbleibt - also ein neuer, unlösbarer Widerspruch. Sobald wir einmal eingesehn haben - und zu dieser Einsicht hat uns schließlich niemand mehr verholfen als Hegel selbst -, daß die so gestellte Aufgabe der Philosophie weiter nichts heißt als die Aufgabe, daß ein einzelner Philosoph das leisten soll, was nur die gesamte Menschheit in ihrer fortschreitenden Entwicklung leisten kann sobald wir das einsehn, ist es auch am Ende mit der ganzen Philosophie im bisherigen Sinn des Worts. Man läßt die auf diesem Weg und für jeden einzelnen unerreichbare ,absolute Wahrheit" laufen und jagt dafür den erreichbaren relativen Wahrheiten nach auf dem Weg der positiven Wissenschaften und der Zusammenfassung ihrer Resultate vermittelst des dialektischen Denkens» (ENGELS, 1962, p.270, a grifo o que foi apagado).

${ }_{22}$ «Der große Grundgedanke, daß die Welt nicht als ein Komplex von fertigen Dingen zu fassen ist, sondern als ein Komplex von Prozessen, worin die scheinbar stabilen Dinge nicht minder wie ihre Gedankenabbilder in unserm Kopf, die Begriffe, eine ununterbrochene Veränderung des Werdens und Vergehens durchmachen, in der bei aller scheinbaren 
Assim, quando Walling pretendia assinalar a presença de um dogmatismo à la hegeliana, tendo em conta a "dialética da Natureza" exposta por Engels, descurava precisamente o sentido em que o autor alemão se referia a uma tal dialética, por sua vez, no sentido de um devir da natureza (mas também da sociedade) e o fim da visão fixa própria de uma (determinada) conceção metafísica (cf. ENGELS, 1962, p.295).

Com o mesmo objetivo crítico, o autor americano assinalava uma outra passagem de Engels, saltando, precisamente, por cima de umas linhas relevantes para a compreensão da mesma:

Ora, foram justamente as oposições diametrais representadas como inconciliáveis e insolúveis, as linhas de demarcação e as diferenças de classe fixadas à força que deram à ciência teórica da Natureza, nos tempos modernos, o seu caráter metafísico definido. Reconhecer que estas oposições e estas diferenças existem realmente na Natureza, mas apenas com uma validade relativa; que em compensação essa fixidez e esse valor absoluto que se lhes atribuía somente são introduzidos na Natureza pela nossa reflexão, tal é o essencial da conceção dialética da Natureza [dialektischen Auffassung der Natur]. Podemos chegar aí sob a pressão dos factos que se acumulam na ciência da Natureza; chegaremos lá mais facilmente se abordarmos o caráter dialético desses factos com a consciência das leis do pensamento dialético. De qualquer modo, a ciência da Natureza tem feito tais progressos que já não pode fugir à compreensão dialética (ENGELS, 1975c, p.14, a grifo o que foi referido por Walling) ${ }^{23}$.

Assinalando somente a parte final, Walling pretendia provar um dogmatismo dialético... É preciso, por isso, continuar a confrontar o contexto das passagens citadas com aquilo em que consistia a maneira de

\footnotetext{
Zufälligkeit und trotz aller momentanen Rückläufigkeit schließlich eine fortschreitende Entwicklung sich durchsetzt - dieser große Grundgedanke ist, namentlich seit Hegel, so sehr in das gewöhnliche Bewußtsein übergegangen, daß er in dieser Allgemeinheit wohl kaum noch Widerspruch findet».

${ }^{23}$ «Es sind aber grade die als unversöhnlich und unlösbar vorgestellten polaren Gegensätze, die gewaltsam fixierten Grenzlinien und Klassenunterschiede, die der modernen theoretischen Naturwissenschaft ihren beschränkt-metaphysischen Charakter gegeben haben. Die Erkenntnis, daß diese Gegensätze und Unterschiede in der Natur zwar vorkommen, aber nur mit relativer Gültigkeit, daß dagegen jene ihre vorgestellte Starrheit und absolute Gültigkeit erst durch unsre Reflexion in die Natur hineingetragen ist - diese Erkenntnis macht den Kernpunkt der dialektischen Auffassung der Natur aus. Man kann zu ihr gelangen, indem man von den sich häufenden Tatsachen der Naturwissenschaft dazu gezwungen wird; man gelangt leichter dahin, wenn man dem dialektischen Charakter dieser Tatsachen das Bewußtsein der Gesetze des dialektischen Denkens entgegenbringt, jedenfalls ist die Naturwissenschaft jetzt so weit, daß sie der dialektischen Zusammenfassung nicht mehr entrinnt».
} 
investigar da metafísica para os dois fundadores da conceção materialista da história:

\begin{abstract}
Para o metafísico, as coisas e os seus reflexos no pensamento, os conceitos, são objetos de investigação isolada, a considerar um após outro e um sem o outro, fixos, rígidos, dados de uma vez para sempre. O metafísico pensa antes por opostos sem mediação: diz sim, sim, não, não; o que vai mais longe não vale nada. Para ele, uma coisa existe ou não existe; uma coisa não pode ser ao mesmo tempo ela e outra. O positivo e o negativo excluem-se absolutamente; a causa e o efeito opõemse de modo igualmente rígido. [...] o modo de ver metafísico, por mais justificado e necessário que seja nos amplos domínios cuja extensão varia consoante a natureza do objeto, esbarra sempre, mais tarde ou mais cedo, numa barreira para lá da qual se torna restrito, limitado, abstrato, e se perde em contradições insolúveis [unlösliche Widersprüche], pela simples razão de que perante os objetos singulares se esquece da sua conexão [Zusammenhang]; perante o seu ser, da sua evolução e da sua morte; perante o seu repouso, do seu movimento; enfim, as árvores impedem-no de ver a floresta (ENGELS, 1975c, pp.20$21)^{24}$.
\end{abstract}

Isto é, para Engels, encontrava-se em causa superar um tipo de conceção que se debruçava sobre a realidade como se esta se tratasse de uma série de abstrações (em relação ao próprio devir), tornando o objeto de investigação algo isolado e fixo. Num tal objeto, toda a contradição seria insolúvel e jamais quaisquer opostos (reais) poderiam agir reciprocamente ou dar lugar a algo novo contendo em parte ambos, ou seja, jamais poderiam devir. Este ponto de vista metafísico excluiria o movimento, então, toda a evolução. Este seria o ponto de vista combatido por Engels nas suas passagens. Porém, não foi o ponto de vista destacado por Walling.

A conceção de uma dialética da Natureza, em Engels, não era mais do que uma parte da conceção materialista da história, isto é, da ação recíproca de todos os fatores reais do desenvolvimento histórico (a "ação recíproca" pela qual Walling passa sem comentar).

24 « Für den Metaphysiker sind die Dinge und ihre Gedankenabbilder, die Begriffe, vereinzelte, eins nach dem andern und ohne das andre zu betrachtende, feste, starre, ein für allemal gegebne Gegenstände der Untersuchung. Er denkt in lauter unvermittelten Gegensätzen: seine Rede ist ja, ja, nein, nein, was darüber ist, ist vom Übel. Für ihn existiert ein Ding entweder, oder es existiert nicht: ein Ding kann ebensowenig zugleich es selbst und ein andres sein. Positiv und negativ schließen einander absolut aus; Ursache und Wirkung stehn ebenso in starrem Gegensatz zueinander. [...] und die metaphysische Anschauungsweise, auf so weiten, je nach der Natur des Gegenstandes ausgedehnten Gebieten sie auch berechtigt und sogar notwendig ist, stößt doch jedesmal früher oder später auf eine Schranke, jenseits welcher sie einseitig, borniert, abstrakt wird und sich in unlösliche Widersprüche verirrt, weil sie über den einzelnen Dingen deren Zusammenhang, über ihrem Sein ihr Werden und Vergehn, über ihrer Ruhe ihre Bewegung vergißt, weil sie vor lauter Bäumen den Wald nicht sieht». 
Por conseguinte, para o autor alemão não se tratava de um desenvolvimento com vista a uma "solução definitiva" tal como Hegel acabara por fazer ao fechar o seu sistema em contradição com o seu próprio método (cf. ENGELS, 1962, pp.268-270), isto é, ao fechar a sua doutrina contra a sua dialética:

[...] para a dialética, que apreende as coisas e os seus reflexos concetuais essencialmente na sua conexão, na sua concatenação [Verkettung], no seu movimento, no seu nascimento e no seu fim, os processos atrás mencionados são outras tantas verificações do comportamento que lhe é peculiar. A Natureza é o teste [Probe] da dialética e devemos dizer em abono da moderna ciência da Natureza que forneceu a esse teste uma rica colheita de dados que aumenta todos os dias, o que demonstra que na Natureza as coisas se passam, em última análise, dialeticamente e não metafisicamente, que a Natureza não se move na eterna monotonia de um ciclo constantemente repetido, mas percorre, sim, uma história efetiva [wirkliche Geschichte] (ENGELS, 1975c, p.22, a grifo o que o próprio autor veio a acrescentar em Die Entwicklung des Sozialismus von der Utopie zur Wissenschaft, 1975c, p.607) ${ }^{25}$.

Era precisamente esta conceção dialética que permitia a Marx e a Engels defender a impossibilidade de uma conceção fechada e fixa da realidade: «Na verdade, qualquer reflexão do sistema do Mundo no pensamento está e permanece limitada objetivamente pela situação histórica, e subjetivamente pela natureza física e psíquica do seu autor» (ENGELS, 1975 b, p.35, cf. idem, p.78) ${ }^{26}$, ou seja, qualquer suposta "verdade eterna" não será mais do que o exagero de uma verdade relativa, não se pode escapar à história da mesma, o que não quer dizer que não haja realidade objetiva.

Parece, tendo isto em conta, poder ser compreendido o que está na base da crítica engelsiana à incognoscibilidade da "coisa em si", que à primeira vista se assemelhava à perspetiva pragmatista:

\footnotetext{
${ }^{25}$ «Für die Dialektik dagegen, die die Dinge und ihre begrifflichen Abbilder wesentlich in ihrem Zusammenhang, ihrer Verkettung, ihrer Bewegung, ihrem Entstehn und Vergehn auffaßt, sind Vorgänge wie die obigen, ebensoviel Bestätigungen ihrer eignen Verfahrengsweise. Die Natur ist die Probe auf die Dialektik, und wir müssen es der modernen Naturwissenschart nachsagen, daß sie für diese Probe ein äußerst reichliches, sich täglich häufendes Material geliefert und damit bewiesen hat, daß es in der Natur, in letzter Instanz, dialektisch und nicht metaphysisch hergeht, daß sie sich nicht im ewigen Einerlei eines stets wiederholten Kreises bewegt, sondern eine wirkliche Geschichte durchmacht».

26 «Tatsächlich ist und bleibt jedes Gedankenabbild des Weltsystems objektiv durch die geschichtliche Lage und subjektiv durch die Körper- und Geistesverfassung seines Urhebers beschränkt».
} 
[Dizem os agnósticos neokantianos: a] "coisa em si” está para além do nosso alcance de vista. A isto há muito que Hegel respondeu: Se se conhecem todas as qualidades de uma coisa, conhece-se a própria coisa; só resta o facto de a coisa existir fora de nós; e quando os sentidos nos tiverem ensinado este facto, teremos abarcado o último resto da coisa em si, a celebrizada e incognoscível [unknowable] Ding an sich de Kant. A isto pode acrescentar-se que no tempo de Kant o nosso conhecimento dos objetos naturais era na verdade tão fragmentário que ele bem poderia suspeitar que havia, por detrás do pouco que conhecíamos sobre cada um deles, uma misteriosa "coisa em si". Mas uma após outra estas coisas inapreensíveis [ungraspable] foram apreendidas, analisadas $e$, $o$ que é mais, reproduzidas pelo progresso gigantesco da ciência; $e$ aquilo que podemos produzir não poderemos certamente considerar como incognoscível. [...] Os químicos modernos declaram que assim que se conhece a composição química seja de que corpo for, este pode ser formado a partir dos seus elementos (ENGELS, 1908, p.21, Walling chegou a referir o que se apresenta em grifo ${ }^{27}$.

Ou seja, não estaria apenas em causa uma possibilidade prática de conhecimento, mas também o decreto de uma impossibilidade de se conhecer uma tal "coisa em si". A experiência subjetiva de uma "coisa em si", como se dava pragmaticamente, comportaria um caráter essencialmente passivo (esperar para ver no que dá) em comparação com uma prática social em que a experiência não aparece como fator determinante, mas apenas como um momento, por sua vez, não haveria "coisa em si" que subsistisse perante a transformação humana (dialética) da realidade objetiva 28

${ }^{27}$ «[...] "thing in itself" is beyond our ken. To this Hegel, long since, has replied: If you know all the qualities of a thing, you know the thing itself; nothing remains but the fact that the said thing exists without us ; and when your senses have taught you that fact, you have grasped the last remnant of the thing in itself, Kant's celebrated unknowable Ding an sich. To which it may be added, that in Kant's time our knowledge of natural objects was indeed so fragmentary that he might well suspect, behind the little we knew about each of them, a mysterious "thing in itself". But one after another these ungraspable things have been grasped, analyzed, and, what is more, reproduced by the giant progress of science; and what we can produce, we certainly cannot consider as unknowable. [...] Modern chemists declare that as soon as the chemical constitution of no matter what body is known, it can be built up from its elements».

${ }^{28} \mathrm{Na}$ rejeição da dialética, Walling encontra-se mais próximo a James, a quem busca respaldo para diminuir o contributo de Hegel para a filosofia (cf. WALLING, 1913, pp.379380), o que não apenas embate de frente com algumas posições de Dewey, como seguramente contradiz Peirce, principalmente quanto a um curioso comentário deste (para o qual não nos resta espaço para suficiente detalhe): «A verdade é que o pragmaticismo está intimamente ligado ao idealismo absoluto de Hegel» (The truth is that pragmaticism is closely allied to the Hegelian absolute idealism, 1955b, pp.266-267). Peirce referia-se a uma relação da realidade com o pensar, o pensamento constituiria a terceira categoria, 
Não obstante a formação hegeliana, tanto Marx como Engels foram bastante críticos de Hegel ${ }^{29}$, a dialética idealista hegeliana não pode ser vista como simplesmente transposta para uma dialética materialista (cf. ENGELS, 1975c, p.115), quer dizer, simplesmente invertida com o objetivo de conceber um "novo ponto de vista". Os dois autores alemães, pelo exposto, não apenas não demandaram por "soluções definitivas" e "verdades eternas", como apenas o conseguiram por não contrariaram o principal sentido da dialética - o devir -, e ao darem um novo chão... onde pôr os pés... a terão transformado.

\section{Engels, Marx e o fim de uma Odisseia}

Ao se considerar a citação de Walling de uma passagem de Das Kapital de que Engels se serviu, assoma de igual modo determinante perceber o contexto da mesma. Será, porventura, o fator económico (a despeito de tudo o que era feito crer), o fator mais adequado para se compreender como a dialética hegeliana é alegadamente superada por um novo sentido em Marx e Engels e assim perceber se esta o conduziu ou não a um "determinismo". É nas seguintes palavras que Marx se expressou:

A centralização dos meios de produção e a socialização do trabalho atingem um ponto em que se tornam incompatíveis com o seu invólucro capitalista [kapitalistischen Hülle]. Ele é rompido. Soa a hora da propriedade privada capitalista. Os expropriadores são expropriados. $O$ modo de apropriação capitalista, proveniente do modo de produção capitalista, portanto, a propriedade privada capitalista, é a primeira negação da propriedade privada individual, fundada em trabalho próprio. Mas a produção capitalista engendra [erzeugt] com a necessidade de um processo natural [Naturprozesses] a sua própria negação. É a negação da negação [Es ist Negation der Negation]. Esta não restabelece a propriedade privada, mas, sim, a propriedade individual na base das conquistas da era capitalista: da cooperação e da posse comum da terra e dos meios de produção produzidos pelo próprio trabalho. A transformação da propriedade privada fragmentada assente em trabalho próprio do indivíduo em [propriedade privada] capitalista, é, naturalmente, um processo

mediação, terceiridade, elemento essencial da realidade para o pragmatismo, ao passo que Hegel, e aqui o motivo por que este falhara o pragmatismo, degradaria a terceira categoria a um mero estágio do pensar.

${ }^{29}$ Chegaram a considerar o sistema hegeliano como um aborto colossal (kolossale Fehlgeburt), este sofreria de uma contradição interna incurável: por um lado tinha como pressuposto essencial a conceção histórica segundo a qual a história humana é um processo de desenvolvimento que, pela sua natureza, não pode encontrar na descoberta de uma chamada verdade absoluta a sua conclusão intelectual; mas, por outro lado, afirmava ser a essência mesma desta verdade absoluta. O que contrariava o próprio pensamento dialético segundo os autores (cf. ENGELS, 1975c, pp.23-24). 
incomparavelmente mais longo, duro e difícil do que a transformação da propriedade capitalista, já efetivamente assente num funcionamento de produção social, em [propriedade] social. Tratava-se ali da expropriação da massa do povo por poucos usurpadores, aqui trata-se da expropriação de poucos usurpadores pela massa do povo (MARX, 1962, VII, $24, \S 7$, p.791, a grifo o que foi referido por Walling) ${ }^{30}$.

Segue-se o contexto em que Engels o citou, alterando a exatidão das palavras em que Marx se pronunciara (é esta a versão usada na tradução para inglês de que Walling se serve):

Só depois de concluir a sua prova [Beweis] económica e histórica é que Marx continua: "O modo capitalista de produção e de apropriação, que é o mesmo que dizer propriedade privada capitalista, constitui a primeira negação da propriedade privada que se funda no trabalho individual, a negação da produção capitalista será engendrada com a necessidade de um processo natural. É a negação da negação", etc. [...] Portanto, caraterizando o fenómeno como negação da negação, Marx não pensa em demonstrar de tal forma a necessidade histórica [geschichtlich notwendigen]. Pelo contrário, depois de demonstrar por intermédio da história como, de facto, o fenómeno em parte se realizou e em parte terá forçosamente de se realizar ainda, é que Marx o designa, além disso, como um fenómeno que se processa de acordo com uma lei dialética [dialektischen Gesetz]. Só isto (ENGELS, 1975c, p.245, a grifo o que foi referido por Walling a partir de Engels) ${ }^{31}$.

\footnotetext{
30 «Die Zentralisation der Produktionsmittel und die Vergesellschaftung der Arbeit erreichen einen Punkt, wo sie unverträglich werden mit ihrer kapitalistischen Hülle. Sie wird gesprengt. Die Stunde des kapitalistischen Privateigentums schlägt. Die Expropriateurs werden expropriiert. Die aus der kapitalistischen Produktionsweise hervorgehende kapitalistische Aneignungsweise, daher das kapitalistische Privateigentum, ist die erste Negation des individuellen, auf eigne Arbeit gegründeten Privateigentums. Aber die kapitalistische Produktion erzeugt mit der Notwendigkeit eines Naturprozesses ihre eigne Negation. Es ist Negation der Negation. Diese stellt nicht das Privateigentum wieder her, wohl aber das individuelle Eigentum auf Grundlage der Errungenschaft der kapitalistischen Ära: der Kooperation und des Gemeinbesitzes der Erde und der durch die Arbeit selbst produzierten Produktionsmittel. Die Verwandlung des auf eigner Arbeit der Individuen beruhenden, zersplitterten Privateigentums in kapitalistisches ist natürlich ein Prozeß, ungleich mehr langwierig, hart und schwierig als die Verwandlung des tatsächlich bereits auf gesellschaftlichem Produktionsbetrieb beruhenden kapitalistischen Eigentums in gesellschaftliches. Dort handelte es sich um die Expropriation der Volksmasse durch wenige Usurpatoren, hier handelt es sich um die Expropriation weniger Usurpatoren durch die Volksmasse».

31 «Erst jetzt, nachdem Marx mit seinem historisch-ökonomischen Beweis fertig ist, fährt er fort: „Die kapitalistische Produktions- und Aneignungsweise, daher das kapitalistische Privateigentum, ist die erste Negation des individuellen, auf eigne Arbeit gegründeten Privateigentums. Die Negation der kapitalistischen Produktion wird durch sie selbst, mit der Notwendigkeit eines Naturprozesses, produziert. Es ist Negation der Negation" usw.
} 
Quer dizer, o modo de produção capitalista superava um estado de propriedade individual fundado no próprio trabalho (por exemplo, manufatura, pequeno comércio, etc.), uma vez que autoproduzia (pela concorrência), para um número reduzido de indivíduos, uma propriedade individual assente no trabalho de outrem através de uma maior capacidade produtiva.

O sistema capitalista com o seu respetivo modo de apropriação engendrava (autoproduzia) a sua própria negação. Isto porque o desenvolvimento do sistema capitalista, à medida que acumulava capital em "poucos usurpadores", colocava na maioria dos outros, na "massa do povo", a quase totalidade da produção, ou seja, engendrava as condições da sua própria destruição - a propriedade coletiva produzida pelo próprio trabalho (o que constituirá a chamada "contradição insanável" do capitalismo produz riqueza quem não a possui e possui riqueza quem não a produz -, por exemplo, cf. ENGELS, 1975c, pp.249-250).

Ademais, Marx estaria a pensar em termos de negação da negação o que não significava voltar ao que havia dantes, isto é, agora nega-se o que se negou e volta-se ao mesmo. Ao invés, a negação da negação tratava de acrescentar algo novo sem perder os elementos do ponto de partida, mas também, tratava de uma "tendência histórica da acumulação capitalista" (geschichtliche Tendenz der kapitalistischen Akkumulation) - o que não se refere a uma necessidade histórica "absoluta", porquanto a sua "força natural" será relativa historicamente, ora, os elementos por que se desenvolve determinado sistema económico valem para si objetivamente, mas não eternamente. É o mesmo sentido que Marx expressava na mesma obra ao dizer:

[...] quanto maior for a camada de lázaros da classe operária e o exército industrial de reserva, tanto maior será o pauperismo oficial. Esta é a lei geral absoluta da acumulação capitalista [Dies ist das absolute, allgemeine Gesetz der kapitalistischen Akkumulation]. À semelhança do que se passa com todas as outras leis, esta lei é modificada na sua realização por múltiplas circunstâncias, [...] [além disso,] na medida em que o capital se acumula, a situação do operário - seja qual for a sua paga, alta ou baixa - tem de piorar (MARX, 1962, VII, 23, § 4, pp.673-675, grifo do autor) ${ }^{32}$.

[...] Indem Marx also den Vorgang als Negation der Negation bezeichnet, denkt er nicht daran, ihn dadurch beweisen zu wollen als einen geschichtlich notwendigen. Im Gegenteil: Nachdem er geschichtlich bewiesen hat, daß der Vorgang in der Tat teils sich ereignet hat, teils noch sich ereignen muß, bezeichnet er ihn zudem als einen Vorgang, der sich nach einem bestimmten dialektischen Gesetz vollzieht. Das ist alles».

32 «Je größer endlich die Lazarusschichte der Arbeiterklasse und die industrielle Reserve armee, desto größer der offizielle Pauperismus. Dies ist das absolute, allgemeine Gesetz der kapitalistischen Akkumulation. Es wird gleich allen andren Gesetzen in seiner 
No essencial, Marx apenas exprime uma tendência do desenvolvimento do sistema capitalista, reiterando, quanto mais capital se acumula na posse de uma das classes (a dominante - capitalista) menos terá a outra (a dominada - proletariado). Isto não consistiria em especulação, mas na verificação do desenvolvimento económico vigente.

Quanto à descrição de uma "lei geral da acumulação capitalista", seria apenas isso, geral. Porquanto, se se tratasse de capitalismo e acumulação, teria de ter um resultado regular para ter "força de lei", e, na verdade, tudo apontava para que tivesse. Dificilmente se poderá dizer que não existiu acumulação constante de capital por um número reduzido de indivíduos acompanhado das suas "habituais" consequências ${ }^{33}$.

Em conformidade com o que fora exposto em relação à conceção materialista da história, este "processo natural" tratava de uma lei histórica, transitória, mas "necessária" (daí a analogia com as "leis da Natureza") no que ao sistema capitalista dirá respeito (enquanto período histórico), dada a sua peculiar organização dos modos de produção. Serão os depauperados o produto da socialização da produção acima descrita, é uma "tendência histórica" própria do capitalismo (não se encontrava em períodos históricos anteriores, mesmo no período imediatamente anterior - o feudalismo -, pois, a cada período, as suas "leis").

A concorrência capitalista impele os diferentes detentores de capital a procurar a maior acumulação de capital que possam conseguir para

\footnotetext{
Verwirklichung durch mannigfache Umstände modifiziert, [...] Es folgt daher, daß im Maße wie Kapital akkumuliert, die Lage des Arbeiters, welches immer seine Zahlung, hoch oder niedrig, sich verschlechtern muß».

33 Já Karl Popper (1902-1994), autor do qual já foi assinalada uma perspetiva de "conciliação" de Marx com o pragmatismo, havia saltado estas partes que expunham o entendimento do autor alemão acerca das "leis gerais" do capitalismo. Popper pretendia denunciar o caráter não científico e dogmático das teses de Das Kapital, enunciando aquilo que considerava ser uma "lei da miséria crescente" (law of increasing Misery), para tal cita a passagem, que oportunamente se deu conta, da seguinte maneira: «...the larger is the number of those who are officially recognized as paupers. This is the absolute and general law of capitalist accumulation...» (1945, p.174), faltou o que seria cortado pelas reticências: "Es wird gleich allen andren Gesetzen in seiner Verwirklichung durch mannigfache Umstände modifiziert". Por um lado, não cabe aqui dirimir se existe ou não cientificidade no marxismo, porém, parece não ser esta a melhor maneira de tentar provar que não existe, mormente porque não apenas não se encontra uma tal "lei" em Marx, como parece ser uma interpretação abusiva do que constituirá a "socialização dos meios de produção" e a "acumulação de capital". E, por outro lado, se Popper julgava poder provar que Marx estava errado ao mostrar que a miséria afinal não havia crescido nas nações do capitalismo avançado, a verdade é que Marx não pensava apenas na realidade interna de cada nação (não se pode avaliar o sistema por esta ou por aquela nação), mas em termos de "mercado mundial", ou seja, as condições de todos os trabalhadores e nações do mundo estariam interconectadas, são recíprocas, é a "força da anarquia da produção capitalista" (internacional) que força a "tendência" assinalada (por exemplo, cf. ENGELS, 1975c, pp.254-256; MARX, 1961, p.639).
} 
sobreviver uns aos outros, a partir do trabalho assalariado, uma vez que sem produção não há capital real (por exemplo, cf. MARX, 1962, IV, 12, § 4, p.377). É precisamente o que Engels pretendia expressar ao dizer que "Marx não pensa em demonstrar de tal forma a necessidade histórica. Pelo contrário, depois de demonstrar por intermédio da História como, de facto, o fenómeno em parte se realizou e em parte terá forçosamente de se realizar ainda..." é que se pode então retirar alguma "tendência" com "força de lei". Portanto, não se tratava de um dogma, mas do processo real de vida dada a economia capitalista.

Nada disto parece desmentir o sentido que Engels expunha naquela carta a Joseph Bloch (1850-1923), evocada por Walling com o propósito de secundarizar a economia (ou, pelo menos, de lhe equivaler os restantes fatores da realidade social) com vista a mostrar que os próprios fundadores teriam tido consciência de que este fator talvez não desempenhasse o papel que lhe fora enfaticamente atribuído.

$\mathrm{Na}$ verdade, precisamente em sentido oposto ao de Walling, Engels parece apenas pretender assinalar a importância de outros fatores, sem nunca tornar despicienda a economia. Para isso talvez convenha regressar à referida carta (que o autor americano não terá lido, uma vez que a cita e parece conhecer somente a partir da introdução feita pelo tradutor da obra):

Segundo a conceção materialista da história, o momento em última instância determinante [in letzter Instanz bestimmende], na história, é a produção e reprodução da vida real. Nem Marx nem eu alguma vez afirmámos mais. Se agora alguém torce isso [afirmando] que o momento económico é o único determinante, transforma aquela proposição numa frase que não diz nada, abstrata, absurda. A situação [Lage] económica é a base [Basis], mas os diversos momentos da superstrutura [Überbau] - formas políticas da luta de classes e seus resultados: constituições estabelecidas pela classe vitoriosa uma vez ganha a batalha, etc., formas jurídicas, e mesmo os reflexos [Reflexe] de todas estas lutas reais nos cérebros dos participantes, teorias políticas, jurídicas, filosóficas, visões [Anschauungen] religiosas e o seu ulterior desenvolvimento em sistemas de dogmas - exercem também a sua influência [Einwirkung] sobre o curso das lutas históricas e determinam em muitos casos preponderantemente [vorwiegend] a forma delas. Há uma ação recíproca de todos estes momentos, em que, finalmente, através de todo o conjunto infinito de casualidades (isto é, de coisas e eventos cuja conexão interna é entre eles tão remota ou é tão indemonstrável que nós a podemos considerar como nãoexistente, a podemos negligenciar), o movimento económico vem ao de cima como necessário. Senão, a aplicação da teoria a um qualquer período da história seria mais fácil do que a resolução de uma simples equação de primeiro grau. Nós fazemos a nossa história nós próprios, mas, em primeiro lugar, com pressupostos e condições muito determinados. Entre eles,

Engels, Marx e o pragmatismo: a odisseia de William English Walling - Paulo Fernando Rocha Antunes 
os económicos são finalmente os decisivos. Mas também os políticos, etc., mesmo a tradição que assombra as cabeças dos homens, desempenham um papel, se bem que não o decisivo (ENGELS, 1967b, p.463, grifos do autor) ${ }^{34}$.

Confirma-se, assim, o caráter da economia enquanto produção do próprio viver: desde que os seres humanos precisem criar as condições de sua sobrevivência terão sempre de as produzir coletivamente (pois isoladamente não existe qualquer processo de socialização, portanto, tornase quase historicamente irrelevante). Aí, dependerá como produzem o próprio viver, se com as mesmas condições apropriadas privadamente, cooperativamente, comummente ou de outra maneira qualquer. Será sobre esta base que a chamada superestrutura se ergue, contudo, não de forma mecânica ou determinada, pois esta também exercerá a sua influência. Será este o caráter "decisivo" da economia.

Para Marx e Engels toda esta nova conceção materialista da história só seria possível graças à transformação do que a dialética era para Hegel essencialmente idealista, relato de um progresso inabalável do Espírito (Geist), desvirtuada pela sua ânsia "tipicamente alemã" de fechar um sistema. A dialética para aqueles dois não era posta de fora para dentro ( $d o$ racional para o real). Ao invés, a dialética tratava do próprio desenvolvimento material da realidade, não consistindo em "partir da matéria", mas das condições reais de sobrevivência.

A dialética para Marx e Engels tratava da transitoriedade da sociedade e não havia lugar a um "fim da história", bem como tudo agiria

\footnotetext{
34 «Nach materialistischer Geschichtsauffassung ist das in letzter Instanz bestimmende Moment in der Geschichte die Produktion und Reproduktion des wirklichen Lebens. Mehr hat weder Marx noch ich je behauptet. Wenn nun jemand das dahin verdreht, das ökonomische Moment sei das einzig bestimmende, so verwandelt er jenen Satz in eine nichtssagende, abstrakte, absurde Phrase. Die ökonomische Lage ist die Basis, aber die verschiedenen Momente des Überbaus - politische Formen des Klessenkampfs und seine Resultate - Verfassungen, nach gewonnener Schlacht durch die siegende Klasse festgestellt usw. - Rechtsformen, und nun gar die Reflexe aller dieser wirklichen Kämpfe im Gehirn der Beteiligten, politische, juristische, philosophische Theorien, religiöse Anschauungen und deren Weiterentwicklung zu Dogmensystemen, üben auch ihre Einwirkung auf den Verlauf der geschichtlichen Kämpfe aus und bestimmen in vielen Fällen vorwiegend deren Form. Es ist eine Wechselwirkung aller dieser Momente, worin schließlich durch alle die unendliche Menge von Zufälligkeiten (d.h. von Dingen und Ereignissen, deren innerer Zusammenhang untereinander so entfernt odar so unnachweisbar ist, daß wir ihn als nicht vorhanden betrachten, vernachlässigen können) als Notwendiges die ökonomische Bewegung sich durchsetzt. Sonst ware die Anwendung der Theorie auf eine beliebige Geschichtsperiode ja leichter als die Lösung einer einfachen Gleichung ersten Grades. Wir machen unsere Geschichte selbst, aber erstens unter sehr bestimmten Voraussetzungen und Bedingungen. Darunter sind die ökonomischen die schließlich entscheidenden. Aber auch die politischen usw., ja selbst die in den Köpfen der Menschen spukende Tradition, spielen eine Rolle, wenn auch nicht die entscheidende».
} 
reciprocamente e caberia precisamente procurar perceber tais relações e quais as suas forças motrizes e agir sobre elas.

Neste sentido, recorda-se aquilo em que uma conceção materialista consistia fundamentalmente, segundo Engels:

A rutura com a filosofia de Hegel sucedeu aqui igualmente pelo regresso ao ponto de vista materialista. O que significa que se decidiu conceber o mundo real [wirkliche Welt] - a natureza e a história - tal como se apresenta a quem o aborde sem fantasias idealistas preconcebidas; decidiu-se sacrificar impiedosamente todas as fantasias idealistas impossíveis de conciliar com os factos considerados nas suas próprias relações e não em relações fantásticas. E o materialismo não significa verdadeiramente nada mais. Simplesmente era a primeira vez que se tomava verdadeiramente a sério a conceção materialista do mundo, que se aplicava de modo consequente a todos os domínios considerados do saber - pelo menos nas suas grandes linhas $\left(1962\right.$, p.292) ${ }^{35}$.

O que quererá dizer que a nova conceção materialista não tratava da aplicação de um postulado de onde se pudesse salvar a filosofia com uma nova matriz dedutiva (cf. ENGELS, 1975c, p.89). Pelo contrário, tratava de um vivo repúdio de todas as fantasias de que o ser humano se servira para descrever a realidade ou as "condições reais de sobrevivência", ora, tratava de perceber qual a conexão das "fantasias" com o próprio desenvolvimento real. Posto isto, parece que a reposição deste sentido da conceção materialista da história porá fim a toda uma odisseia.

\section{Conclusão}

Com vista a concluir, dado estar a chegar ao limite o espaço reservado para o efeito proposto, talvez se possa dizer que, num primeiro momento e de acordo com Walling, a prática como critério de verdade se adequa tanto ao marxismo como ao pragmatismo e que tal poderia propiciar a "conciliação" de uma espécie de novo socialismo, um "socialismo pragmatista". Todavia, a conceção de prática de um e de outro é distinta.

\footnotetext{
35 «Die Trennung von der Hegelschen Philosophie erfolgte auch hier durch die Rückkehr zum materialistischen Standpunkt. Das heißt, man entschloß sich, die wirkliche Welt Natur und Geschichte - so aufzufassen, wie sie sich selbst einem jeden gibt, der ohne vorgefaßte idealistische Schrullen an sie herantritt; man entschloß sich, jede idealistische Schrulle unbarmherzig zum Opfer zu bringen, die sich mit den in ihrem eignen Zusammenhang, und in keinem phantastischen, aufgefaßten Tatsachen nicht in Einklang bringen ließ. Und weiter heißt Materialismus überhaupt nichts. Nur daß hier zum erstenmal mit der materialistischen Weltanschauung wirklich Ernst gemacht, daß sie auf allen in Frage kommenden Gebieten des Wissens - wenigstens in den Grundzügen - konsequent durchgeführt wurde».
} 
Para compreender as diferenças, talvez baste retomar a $1 .{ }^{a}$ tese sobre Feuerbach de Marx:

O principal defeito de todo o materialismo até aos nossos dias (o de Feuerbach incluído) é que as coisas, a realidade, o mundo sensível são tomadas apenas sobre a forma do objeto ou da contemplação [Anschauung]; mas não como atividade sensível humana [sinnlich menschliche Tätigkeit], Práxis, não subjetivamente. Por isso aconteceu que o lado ativo foi desenvolvido, em oposição ao materialismo, pelo idealismo mas apenas abstratamente, pois que o idealismo naturalmente não conhece a atividade sensível, real, como tal. Feuerbach quer objetos sensíveis realmente distintos dos objetos do pensamento; mas não toma a própria atividade humana como atividade objetiva [gegenständliche Tätigkeit]. Ele considera, por isso, em "Wesen des Christenthums", apenas a atitude teorética como a genuinamente humana, ao passo que a práxis é tomada e fixada apenas na sua forma de manifestação sórdida e judaica. Não compreende, por isso, o significado da atividade "revolucionária", de crítica prática (MARX, 1978, p.5, grifos do autor) ${ }^{36}$.

De onde saltam à vista, pelo menos, três diferenças ao confrontar com a passagem tal como havia sido citada pelo autor americano. A diferença menos relevante talvez seja a que se refere ao adjetivo "judaica" (jüdischen), adjetivo que procurava ilustrar o burguês interessado exclusivamente nos bens materiais (considerando o que era dito originalmente por Feuerbach). O que provavelmente importava manter, porém, tal adjetivo já havia sido suprimido na tradução de que Walling se serviu $^{37}$.

36 «Der Hauptmangel alles bisherigen Materialismus (den Feuerbachschen mit eingerechnet) ist, daß der Gegenstand, die Wirklichkeit, Sinnlichkeit nur unter der Form des Objekts oder der Anschauung gefaßt wird; nicht aber als sinnlich menschliche Tätigkeit, Praxis; nicht subjektiv. Daher die tätige Seite abstrakt im Gegensatz zu dem Materialismus von dem Idealismus - der natürlich die wirkliche, sinnliche Tätigkeit als solche nicht kennt - entwickelt. Feuerbach will sinnliche - von den Gedankenobjekten wirklich unterschiedne Objekte: aber er faßt die menschliche Tätigkeit selbst nicht als gegenständliche Tätigkeit. Er betrachtet daher im „Wesen des Christenthums” nur das theoretische Verhalten als das echt menschliche, während die Praxis nur in ihrer schmutzig jüdischen Erscheinungsform gefaßt und fixiert wird. Er begreift daher nicht die Bedeutung der ,,revolutionären”, der ,praktisch-kritischen” Tätigkeit».

${ }^{37}$ Passagem agora reproduzida por inteiro na versão inglesa utilizada por Walling: «The chief lack of all materialistic philosophy up to the present, including that of Feuerbach, is that the thing, the reality, sensation is only conceived of under the form of the object which is presented to the eye, but not as human sense activity, "praxis"; not subjectively. It therefore came about that the active side in opposition to materialism was developed from idealism, but only abstractly; this was natural, since idealism does not recognize real tangible facts as such. Feuerbach is willing, it is true, to distinguish objects of sensation from objects existing in thought, but he conceives of human activity itself not as objective activity. He, therefore, in the "Wesen des Christenthums", regards only theoretical activity 
Uma outra diferença, também da responsabilidade do tradutor, trata de não aparecer traduzido, e assim não incluir, a última linha da tese que se refere à parte que trataria da "crítica prática" como parte de uma "atividade revolucionária", isto é, uma componente complementar (ainda que não a principal) da transformação da realidade ${ }^{38}$.

A última diferença, e seguramente a mais relevante, já da responsabilidade do autor, trata da supressão da expressão "não subjetivamente" (not subjectively - nicht subjektiv), o que vem fazer toda a diferença.

A par de uma tentativa de expurgar o marxismo da dialética que fez sua, talvez a propositada supressão de que a práxis concernente à conceção materialista da história não é subjetiva seja o momento mais evidente da odisseia wallingiana em fazer com que algo pareça o que não é.

Ora, se a prática em sede pragmatista não poderia escapar a um subjetivismo, pois visa ser a concretização de algo que fora projetado por um sujeito ${ }^{39}$, a prática em Marx e Engels não coincidiria com tal perspetiva, pois assenta na objetividade da realidade, e privilegia, por isso, o desenvolvimento (material dialético) desta como um todo em ação recíproca. É neste todo que pode haver prática e seguramente projeto, da "atividade sensível humana" (não subjetiva como fora sugerido) ${ }^{40}$.

as generally human, while the "praxis"; is conceived and fixed only in its disgusting form» (ENGELS, 1903, p.129).

${ }^{38}$ Sobre o tradutor Austin Lewis (1865-1944) quase poderia ser escrito um outro artigo. Lewis não apenas opta por traduzir Herrn Eugen Dührings Umwälzung der Wissenschaft (,Anti-Dühring “) por Landmarks of Scientific Socialism (1907) como também não é fiel ao Ludwig Feuerbach und der Ausgang der klassischen deutschen Philosophie escolhendo Feuerbach. The Roots of the Socialist Philosophy (1903) para o intitular. O mesmo tradutor também deixa duas sugestivas introduções e um apêndice onde insiste no combate engelsiano às "soluções definitivas" e às "verdades eternas", como também duvida do total empenho de Engels contra as mesmas; considerando, por fim, que a dialética não deve ser obrigatória para todos os socialistas e que a herança hegeliana deixou um marco de "obscuridade" em Das Kapital...

${ }^{39}$ Como se pode dar conta na paradigmática passagem de Peirce: «Considerando quais os efeitos que concebivelmente [conceivably] podem ter implicações práticas [practical bearings], nós concebemos o objeto da nossa conceção. Então, a nossa conceção destes efeitos é o todo [whole] da nossa conceção do objeto» - «Consider what effects that might conceivably have practical bearings we conceive the object of our conception to have. Then, our conception of these effects is the whole of our conception of the object» (1955a, p.31, grifos nossos).

${ }^{40}$ Mas se em Marx e Engels a questão parece remeter para o desenvolvimento da realidade como um todo, dialético, procurando compreender a ação recíproca desse mesmo todo, para o pragmatismo a questão parece remeter quase exclusivamente para o campo de um êxito subjetivo (quer epistemológico, ontológico, como político), deixando por resolver, por exemplo, a questão do desenvolvimento da realidade, ou seja, de alguma maneira a realidade parece estar dependente do sujeito que conhece pela prática. O que poderia ser confrontado com a "questão fundamental da filosofia" (große Grundfrage Philosophie), o problema da relação do pensar com o ser (cf. ENGELS, pp.274-276), mas isso transcenderia o presente mote. 
Daí que para Walling também seja importante contornar a questão de uma crítica da metafísica do ponto de vista dialético, quer seja hegeliano ou já marcadamente marx-engelsiano. Senão veja-se, o pragmatismo considera a prática como o momento de comprovação de toda a verdade necessariamente particular, isolando a prática (em rigor, a experiência) como uma causa direta de um efeito que servirá como prova de verdade se corresponder ao projetado previamente pelo sujeito. Então, o que será isto senão toda a abstração que Engels repudiava sob a sua crítica à metafísica? 41.

Quanto à conceção materialista da história, a prática não pode ser um momento isolado, tem história e é esta que faz toda a diferença, como assinalava Engels:

[...] podemo-nos ainda interrogar acerca das forças motrizes [treibenden Kräfte] escondidas atrás desses motivos [de ordem ideal], e acerca das causas históricas que se transformam nesses motivos nos cérebros dos homens que atuam. Esta questão nunca foi equacionada pelo antigo materialismo. É por isso que a sua conceção da história, na medida em que tenha alguma, é essencialmente pragmática [wesentlich pragmatisch]; julga tudo segundo os motivos da ação, divide os homens, exercendo uma ação histórica, em almas nobres e não nobres, e constata em seguida regularmente que os nobres são os enganados e os não nobres são os vencedores, donde resulta, para o antigo materialismo, que nada de edificante se pode extrair do estudo da história e, para nós, que, no domínio histórico, o antigo materialismo é infiel a si próprio, porque toma por causas últimas [letzte Ursachen] as forças motrizes ideais nelas ativas, em vez de examinar o que há por detrás delas, e tentar saber quais serão as forças motrizes dessas forças motrizes (1962, pp.297-298, grifo nosso) ${ }^{42}$.

\footnotetext{
${ }^{41}$ Por exemplo, o autor alemão dizia em sequência das passagens já referidas: «[...] causa e efeito [Ursache und Wirkung] são representações que só valem como tais aplicadas a um caso particular, mas que, desde que consideremos esse caso particular na sua conexão geral com o conjunto do Mundo, se misturam, se convertem no quadro da ação recíproca universal em que causas e efeitos se permutam constantemente, em que o que era efeito agora ou aqui se transforma em causa algures ou depois, e vice-versa» - «[...] Ursache und Wirkung Vorstellungen sind, die nur in der Anwendung auf den einzelnen Fall als solche Gültigkeit haben, daß sie aber, sowie wir den einzelnen Fall in seinem allgemeinen Zusammenhang mit dem Weltganzen betrachten, Zusammengehn, sich auflösen in der Anschauung der universellen Wechselwirkung, wo Ursachen und Wirkungen fortwährend ihre Stelle wechseln, das was jetzt oder hier Wirkung, dort oder dann Ursache wird und umgekehrt» (ENGELS, 1975c, pp.21-22).

42 «Andrerseits fragt es sich weiter, welche treibenden Kräfte wieder hinter diesen Beweggründen stehn, welche geschichtlichen Ursachen es sind, die sich in den Köpfen der Handelnden zu solchen Beweggründen umformen? Diese Frage hat sich der alte Materialismus nie vorgelegt. Seine Geschichtsauffassung, soweit er überhaupt eine hat, ist daher auch wesentlich pragmatisch, beurteilt alles nach den Motiven der Handlung, teilt die geschichtlich handelnden Menschen in edle und unedle und findet dann in der Regel, daß
} 
Ao que se poderia acrescentar que $« \mathrm{O}$ ponto de vista do antigo materialismo é a sociedade civil burguesa; o ponto de vista do novo [materialismo é] a sociedade humana, ou a humanidade socializada» (Der Standpunkt des alten Materialismus ist die bürgerliche Gesellschaft, der Standpunkt des neuen die menschliche Gesellschaft oder die gesellschaftliche Menschheit. MARX, 1978, p.7, a passagem refere-se à $10 .^{a}$ tese sobre Feuerbach, também citada por Walling, 1913, p.377).

Com tudo isto em consideração, para que o socialismo de Marx e Engels pudesse ser pragmatista teria de deixar de ser o socialismo de Marx e Engels, deixar de ser dialético, deixar a história e recuperar, por exemplo, o ponto de vista de todo o materialismo anterior (o que não quer dizer que o pragmatismo seja todo ele equivalente a este tipo de materialismo). $\mathrm{O}$ socialismo de Marx e Engels teria de aceitar as "forças motrizes ideias" como se se eximissem à economia (mesmo que num sentido mínimo produção do próprio viver - como assinalado), segundo preconizava Walling ${ }^{43}$. Mais, o socialismo de Marx e Engels teria de aceitar a sociedade civil burguesa como um dado natural, de onde partir, mas também ficar; o que, porventura, tratar-se-á mais propriamente de uma conceção pragmatista, uma vez que esta projeta a partir do vigente com vista a um efeito que se conforme e confirme a sua "verdade" habitual.

Enfim, quem estaria a ler algum autor pragmaticamente? Talvez, e também aludindo à outra epígrafe, Hegel nunca tenha existido para tais odisseias conciliadoras, e, por isso mesmo, haveria um elevado preço a pagar $^{44}$.

die edlen die Geprellten und die unedlen die Sieger sind, woraus dann folgt für den alten Materialismus, daß beim Geschichtsstudium nicht viel Erbauliches herauskommt, und für uns, daß auf dem geschichtlichen Gebiet der alte Materialismus sich selbst untreu wird, weil er die dort wirksamen ideellen Triebkräfte als letzte Ursachen hinnimmt, statt zu unter suchen, was denn hinter ihnen steht, was die Triebkräfte dieser Triebkräfte sind».

43 Não pode cair em esquecimento, por exemplo, que o descuido da dialética era precisamente o que Engels criticava a Dühring, para além de este buscar um sistema socialista fechado.

${ }^{44}$ Muito mais se poderia desenvolver, desde o percurso pessoal que o autor seguiu (talvez $O$ preço que pagou), à influência de Kautsky e o seu "reformismo", Lafargue e o "determinismo económico", os próprios fundadores do pragmatismo, a mútua influência de Hegel e outros traços de uma rejeição do mesmo, os escritos de Marx e Engels entre 18481875 bem como alguns dos anteriores (pelo menos de 1844 a 1847), a influência de Charles Darwin (1809-1882) tanto no marxismo como no pragmatismo, o contexto da II Internacional e a influência dos Bolcheviques; mas tudo isto daria imenso pano para mangas, fica, na melhor das hipóteses, o compromisso de um ulterior aprofundamento da presente temática.

Engels, Marx e o pragmatismo: a odisseia de William English Walling - Paulo Fernando Rocha Antunes 


\section{Referências bibliográficas:}

BOYLAN, James. Revolutionary Lives: Anna Strunsky and William English Walling. Amherst, MA: University of Massachutsetts Press, 1998.

DEWEY, John. An Added Note as to the 'Pratical'. In: Essays in Experimental Logic. Chicago-Illinois: The University of Chicago Press, 1916; pp.330-334.

ENGELS, Friedrich. Anti-Dühring. Tradução de Adelina dos Santos Rodrigues. Lisboa: Editorial Minerva, 1975a; vol. I.

Brief an Conrad Schmidt in Berlin, London, 27. Okt. 1890. MarxEngels Werke, ed. IML (Doravante: MEW). Berlin: Dietz Verlag, 1967a; vol. 37, pp.488-495.

Brief an Joseph Bloch in Königsberg, London, 21. Sept. 1890. MEW, 1967b; vol. 37, pp.462-465.

Carta a Conrad Schmidt em Berlim, 5 de Agosto de 1890. Tradução de José Barata-Moura. MARX, Karl; ENGELS, Friedrich. Obras Escolhidas (Doravante: OE). Lisboa-Moscovo: Editorial «Avante!»-Edições Progresso, 1982a; vol. III, pp.542-544.

. Carta a Joseph Bloch em Königsberg, 21-22 de Setembro de 1890.

Tradução de José Barata-Moura. OE, 1982b; vol. III, pp.547-549.

. Die Entwicklung des Sozialismus von der Utopie zur

Wissenschaft. MEW, 1987; vol. 19, pp.181-228.

. Do Socialismo Utópico ao Socialismo Científico. Tradução do colectivo Edições «Avante!». Lisboa: Editorial «Avante!», 1975 b.

Feuerbach. The Roots of the Socialist Philosophy. Tradução de

Austin Lewis. Chicago: Charles H. Kerr \& Company, 1903.

Herrn Eugen Dührings Umwälzung der Wissenschaft („Anti-

Dühring“). MEW, 1975c; vol. 20, pp.5-303.

. Landmarks of Scientific Socialism. "Anti-Duehring”. Tradução de

Austin Lewis. Chicago: Charles H. Kerr \& Company, 1907.

. Ludwig Feuerbach e o fim da filosofia clássica alemã. In: MARX,

Karl; ENGELS, Friedrich. Sobre a Religião (Escolha dos textos: G. Badia; P. Bange; E. Bottigelli). Tradução de Raquel Silva. Lisboa: Edições 70, 1975d; pp.234-301.

Ludwig Feuerbach und der Ausgang der klassischen deutschen Philosophie. MEW, 1962; vol. 21, pp.259-307.

Socialism. Utopian and Scientific. Tradução de Edward Aveling.

Chicago: Charles H. Kerr \& Company, 1908.

. Socialisme Utopique et Socialisme Scientifique. Tradução de Paul

Lafargue. Paris: Librairie 1'Humanité, 1924. 
HABERMAS, Jürgen. Postscript: some concluding remarks. In: ABOULAFIA, M.; BOOKMAN, M.; KEMP, C. (eds.). Habermas and Pragmatism. New York: Routledge, 2002; pp.223-233.

HEGEL, Georg W. F. Enzyklopädie der philosophischen Wissenschaften im Grundrisse. Erster Teil. Die Wissenschaft der Logik Mit den mündlichen Zusätzen. Werke [in 20 Bänden]. Frankfurt am Main: Suhrkamp Verlag, 1989; vol. 8.

MARX, Karl. Das Kapital. Kritik der politischen Ökonomie; Erster Band, Buch I. MEW, 1962; vol. 23.

. Einleitung [zur Kritik der politischen Ökonomie]. MEW, 1961; vol.13, pp.615-642.

. O Capital. Crítica da Economia Política. Coletivo da tradução composto por José Barata-Moura et al. Lisboa: Editorial «Avante!», 1997; livro 1 , vol. III.

. Teses sobre Feuerbach. Tradução de Álvaro Pina. MARX, Karl; ENGELS, Friedrich. OE, 2008; vol. I, pp.13-16. . Thesen über Feuerbach. MEW, 1978; vol. 3, pp.5-7.

PEIRCE, Charles Sanders. How to Make Our Ideas Clear. BUCHLER, J. (ed.) Philosophical Writings of Peirce (Doravante: PW). New York: Dover Publications, 1955a; pp.23-41.

. The Essentials of Pragmatism. PW, 1955b; pp.251-268.

POPPER, Karl. The Open Society and its Enemies. Volume II: The High Tide of Prophecy Hegel, Marx, and the Aftermath. London: George Routledge \& Sons, ltd., 1945.

SCHNEIROV, Richard. The Odyssey of William English Walling: Revisionism, Social Democracy, and Evolutionary Pragmatism. Joumal of the Gilded Age and Progressive Era vol. 2, n. 4, pp.403-430, Oct. 2003.

UNGER, Roberto Mangabeira. The Self Awakened: Pragmatism Unbound. Cambridge, Massachusetts: Harvard University Press, 2007.

WALLING, William English. Socialism and Pragmatism as seen in the Writings of Marx and Engels (Appendix A); The Larger Aspects of Socialism. New York: The MacMillan Company, 1913; pp.373-385. 